\title{
Characterization of Agro-Well Water in Malwathu Oya Cascade-I in Anuradhapura District of Sri Lanka
}

\author{
M.K.N. Kumari ${ }^{*}$ S. Pathmarajah ${ }^{1}$ and N.D.K. Dayawansa ${ }^{1}$ \\ Postgraduate Institute of Agriculture \\ University of Peradeniya \\ Sri Lanka
}

\begin{abstract}
Malwathu Oya cascade is one of the largest and intensively cultivated small tank cascade systems in Anuradhapura district of Sri Lanka. Agro-wells are the most valuable resource for many farmers in this cascade area as these shallow dug wells have a good potential to sustain crop production during the dry season. However, deterioration of groundwater quality during the dry period has been reported in many parts of the dry zone. Therefore, this study focused on the characterization of agro-well water for its suitability for irrigation in the Malwathu Oya cascade based on its quality and availability. Groundwater samples were collected during March to September 2012 to cover the dry period during which the water quality deterioration has been reported in the dry zone. Electrical Conductivity (EC), pH, concentrations of sodium, potassium, magnesium and calcium, and depth of groundwater were measured from 20 selected agro-wells. The residual sodium carbonate (RSC), sodium adsorption ratio (SAR) and sodium percentage (Na\%) were calculated using the measured parameters. Based on the depth of groundwater available at the end of dry season, 35\%, 25\%, 25\% and $15 \%$ of the wells recorded low, moderate, high and very high groundwater potential, respectively. The EC data showed that 35\%, 55\% and $10 \%$ of the wells had good, doubtful and unsuitable quality of irrigation water, respectively. According to SAR and RSC, all the wells had water good for irrigation. Based on the percentage sodium, $10 \%$ of the wells had excellent, $60 \%$ had good, $25 \%$ had permissible and $5 \%$ had doubtful quality irrigation water. According to the US salinity hazard diagram $40 \%$ of wells had medium salinity and low sodium hazard. Fifty percent of the samples had high salinity and low sodium hazard while $10 \%$ of the samples had very high salinity and medium sodium hazard. Based on the water quality parameters measured, 25\%, 15\%, 50\% and $10 \%$ of the wells in Malwathu Oya cascade fall into good, permissible, doubtful and unsuitable category for irrigation, respectively.
\end{abstract}

Keywords: Agro-wells, groundwater potential, irrigation water quality, Malwathu Oya cascade-I

\section{INTRODUCTION}

Sri Lanka is divided into wet, intermediate and dry zones based on annual average rainfall. Thus, the water availability is limited according to the zone and the water scarcity is the most prominent constraints for agriculture in the dry zone. Hence, historically as well as during

\footnotetext{
1 Department of Agricultural Engineering, Faculty of Agriculture, University of Peradeniya, Sri Lanka

Corresponding author: nadeeta@gmail.com
} 
the past few decades, agriculture was practiced using either rainwater or water collected in village tanks and water diverted from the wet zone by major irrigation schemes.

However, the amount of naturally available water in the dry zone along with the incoming water from the wet zone has been incapable of feeding the commanding areas in the dry zone, particularly during the Yala (dry) season (Dharmasena, 1989). Therefore, an additional and a higher attention have been given to explore the possibility of extracting certain amounts of groundwater for cropping. Hence, large diameter open dug wells (agro-wells) have become increasingly popular among farmers in the dry and intermediate zones of Sri Lanka during the decades of 1980 and 1990. The numbers have expanded up to around 50,000 in an unprecedented manner as those were meant to serve as sources of water for irrigation of agricultural crops during the much drier Yala season as well as during the water stress times of the Maha (wet) season (Jayakody, 2006).

Availability of groundwater above the unweathered bed rock is mostly seasonal in cascade systems of north central province. The diameter of wells ranges from 1.5-5.3 m, the upper range of which is mainly used for small scale irrigated farming. The total depth of wells varies from 3-12 $\mathrm{m}$ depending on the water availability and the elevation. Water table fluctuates within a range of $5 \mathrm{~m}$ (Dharmasena, 1991).

Malwathu Oya cascade-I is one of the meso-catchments of Nuwara Wewa catchment, which is located in the low country dry zone where the availability and quality of water for agriculture has become a major issue. Presence of excessive quantities of salts in groundwater is one of the major constrains for farming under agro-wells in the dry zone of Sri Lanka (Kendaragama, 2000). The surface water quality of Malwathu Oya cascade-I was better in wet flow compared to dry flow and the water quality was still good enough for irrigation even in dry flow in upper and middle parts of the cascade. But the bottom of the cascade showed slight to moderate salinity condition during dry flow (Perera et al., 2011). Based on electrical conductivity (EC) and total dissolved solids (TDS), groundwater quality in Kammalakkulama area which is located in the Malwathu Oya cascade-I was categorized into Class-3 which is permissible for irrigation. Alkalinity values varied between 160-500 $\mathrm{mg} / \mathrm{L}$. Hence, most of the wells are slight to moderately suitable for irrigation purpose (Kumara et al., 2011). Therefore, these findings reveal that both surface and groundwater quality of the cascade has been deteriorated. Irrigation with poor quality water may bring undesirable elements to the soil in excessive quantities affecting soil fertility and crop yield.

Hence, the overall objective of the study was to assess the groundwater for its adequacy and suitability for irrigation based on quality and quantity in the Malwathu Oya cascade during the dry season.

\section{MATERIALS AND METHODS}

\section{Description of study area}

Malwathu Oya Cascade-I is located in $\mathrm{DL}_{1 \mathrm{~b}}$ agro-ecological region of Sri Lanka. Total number of farm families living in the study area is approximately 1100 and the total land area is $25 \mathrm{~km}^{2}$. It belongs to Nuwaragam Palatha - East and Mihintale divisional secretariat areas in the Anuradhapura district. Maha Kalaththewa, Kuda Kalaththewa, Halmillawewa, Bandialankulama, Kammalakkulama, Illuppukanniya, Nelumkanniya, Sattambikulama, Halmillewa, Palugaswewa and Thariyankulama villages of Malwathu Oya cascade-I were 
selected for the study. The total area of the cascade was divided into $1 \mathrm{~km}^{2}$ grids and one agro-well to represent each grid was purposely selected from aforesaid villages to assess the availability and quality of groundwater. Thus a total number of twenty wells located in uplands were selected for the study (Fig. 1).

\section{Assessment of groundwater availability}

Groundwater of selected agro-wells was sampled once a month during the dry season from March to September, 2012. Availability of groundwater was assessed by measuring the depth to groundwater and the depth of well from the surface.

\section{Analysis of water samples}

Water samples were collected from the surface of the agro-wells as no stratification in water quality with depth was anticipated due to heavy utilization of the wells for cultivation. The water samples were transferred into $250 \mathrm{ml}$ clean polyethylene bottles after rinsing two to three times with the groundwater to be sampled. These bottles were tightly closed, labeled and transported to the laboratory of Soil and Water Resources Management, Faculty of Agriculture, Rajarata University of Sri Lanka. EC and pH of samples were measured in-situ using a multi parameter analyzer. Samples were stored below $4^{\circ} \mathrm{C}$. Filtered water samples were used for the other chemical analysis. $\mathrm{Na}^{+}, \mathrm{K}^{+}$were measured by flame photometry while $\mathrm{Ca}^{++}$and $\mathrm{Mg}^{++}$were determined using atomic absorption spectrophotometry (AAS). Carbonate and bicarbonate were measured by acid-base titration.

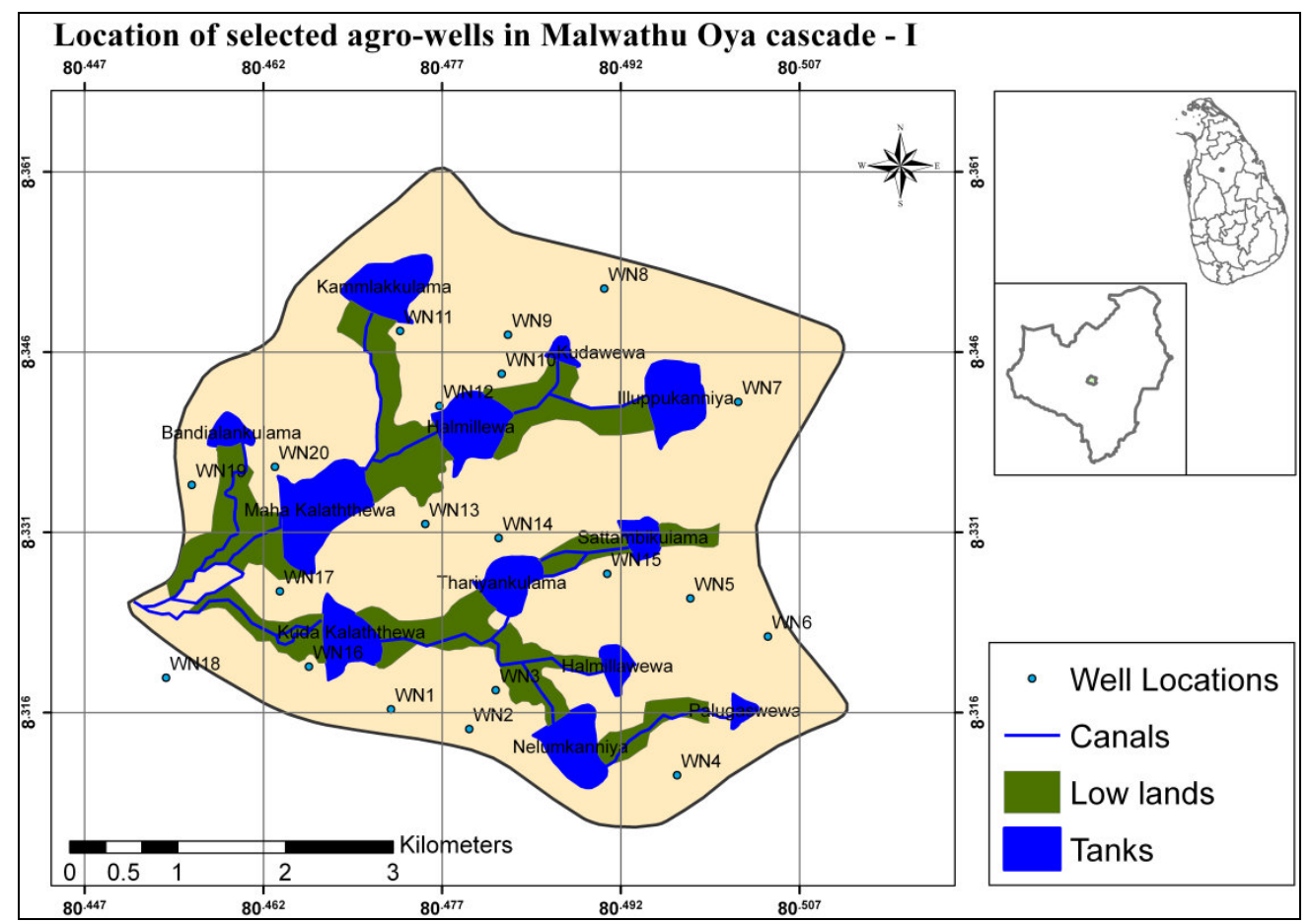

Fig. 1. Location of selected Agro-wells in Malwathu Oya cascade-I. 


\section{Assessment of hazards}

Sodium Absorption Ratio (SAR), Sodium percentage (Na \%) and Residual Sodium Carbonate (RSC) were calculated using aforesaid parameters. Salinity, SAR and RSC values were used to assess the suitability of groundwater for irrigation during the dry season.

\section{Mapping of spatial variability of groundwater}

Once the input data was imported as a point layer into ArcGIS 10.0, geo-database was created to generate the maps of spatial distribution of selected water quality parameters. Interpolation is the process of predicting unknown values using the known values in the vicinity. Point based Inverse Distance Weighted (IDW) interpolation method was used to produce spatial distribution of water quality variables. This interpolation method determines cell values using linearly weighted combination of a set of sample points. The weight is a function of inverse distance.

\section{RESULTS AND DISCUSSION}

\section{Seasonal water availability}

The agro-wells are grouped into four classes namely low $(0.0-0.5 \mathrm{~m})$, moderate $(0.5-1.0 \mathrm{~m})$, high $(1.0-2.0 \mathrm{~m})$ and very high $(>2.0 \mathrm{~m})$ groundwater potentials based on the height of the water column (depth of water) available at the end of the dry season (Perera et al., 2002).

Based on the height of water column available at the end of the dry season (September), $35 \%$ of selected agro-wells had low groundwater potential, $25 \%$ had moderate groundwater potential, $25 \%$ had high groundwater potential and the rest of the selected agro-wells had very high groundwater potential for agriculture (Fig. 2). It is clear from Fig. 2 that water availability is high in the northern part of the cascade where the surface water availability is high. It is highly probable that most of these wells are located along the groundwater flow paths that originate from small tanks. This could be the reason for two more locations in the south also have shown high groundwater potential.

\section{Irrigation water quality in selected wells}

The average $\mathrm{pH}$ of the selected agro-wells varied from 7.6 to 8.4 . The optimum $\mathrm{pH}$ range for irrigation water is 6.5 to 8.4 . Therefore based on $\mathrm{pH}$, all the wells had good quality water for irrigation and well number 16 recorded the highest average $\mathrm{pH}$ of 8.4 (Fig. 3). 


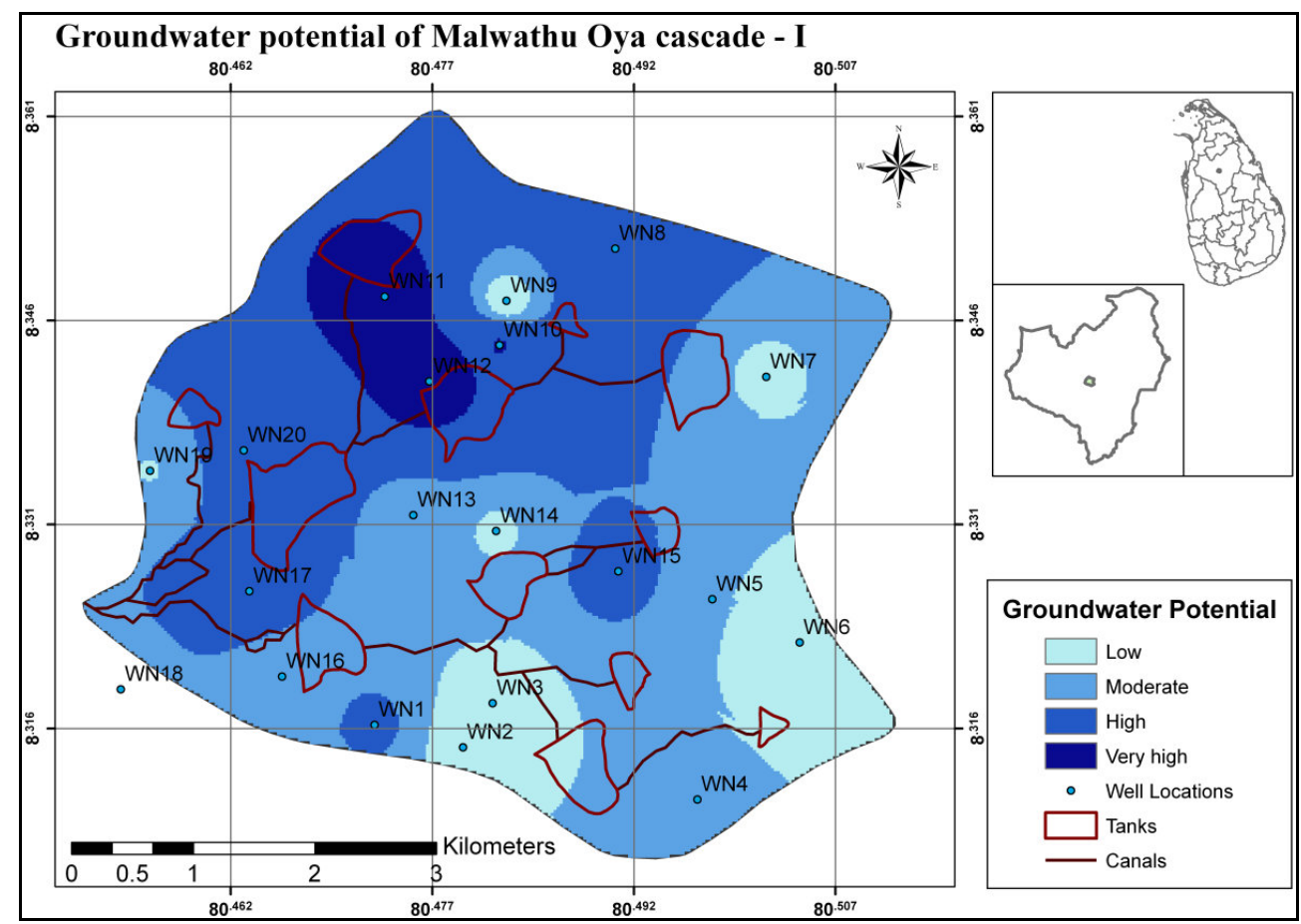

Fig. 2. Spatial variation of groundwater potential in Malwathu Oya cascade-I.

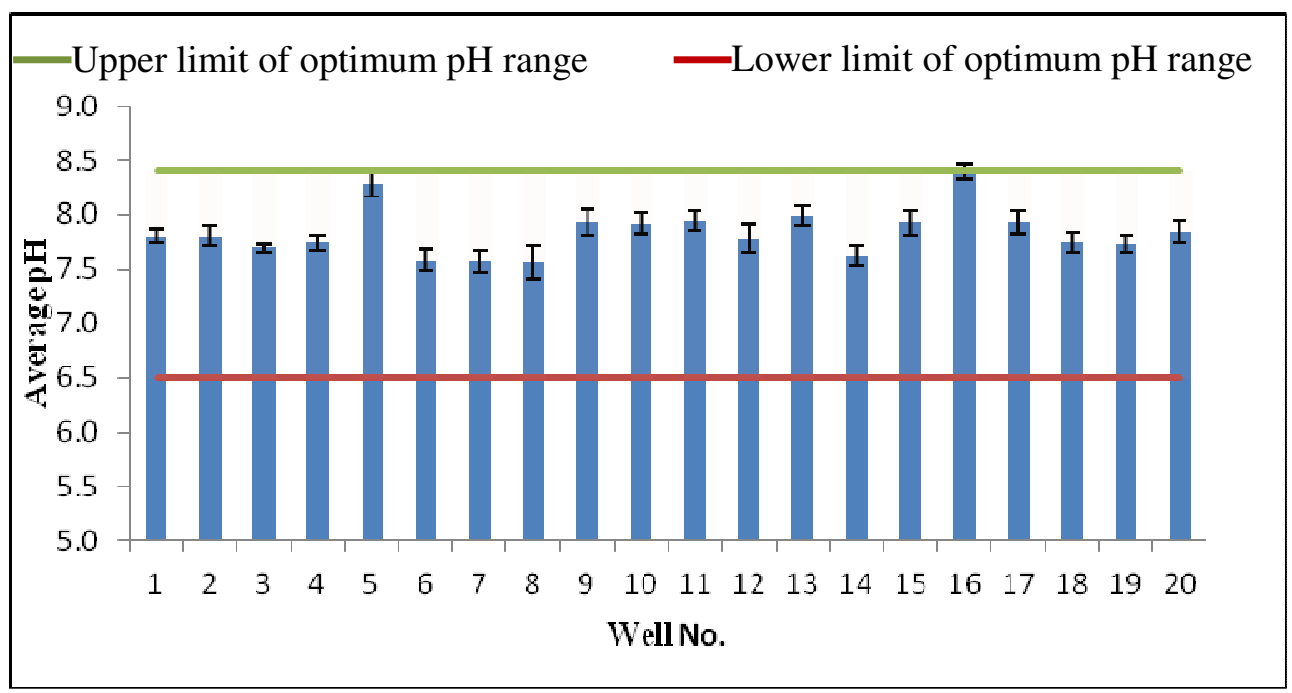

Fig. 3. Average pH values of selected agro-wells.

\section{Salinity hazard}

Water salinity is usually measured by the TDS or the EC. EC is a good measurement of salinity when using groundwater for irrigation. The primary effect of high EC in irrigation water on crop productivity is the inability of the plant to compete with ions in the soil 
solution for water which leads to less water availability to plants (Tatawat \& Chandel, 2008). Classification of groundwater based on salinity hazard was done according to the recommendation of Wilcox (1955). Accordingly, it was grouped as excellent (0.1-0.25 $\mathrm{dS} / \mathrm{m})$, good $(0.25-0.75 \mathrm{dS} / \mathrm{m})$, doubtful $(0.75-2.25 \mathrm{dS} / \mathrm{m})$ and unsuitable $(>2.25 \mathrm{dS} / \mathrm{m})$. Based on EC, $35 \%$ of the wells had good quality, 55\% of the wells had doubtful quality and $10 \%$ of the wells had unsuitable quality of water for irrigation. Spatial variation of average salinity during the study period is shown in Fig. 4. Accordingly, major portion of the cascade falls into the category of 'doubtful'. Lower part of the cascade (i.e. the area surrounding well no. 16 and 17) showed 'unsuitable'. This requires an in-depth study to find out whether it is the result of salt accumulation down the cascade, poor drainage or inherent nature of the soil and the bedrock found in the region.

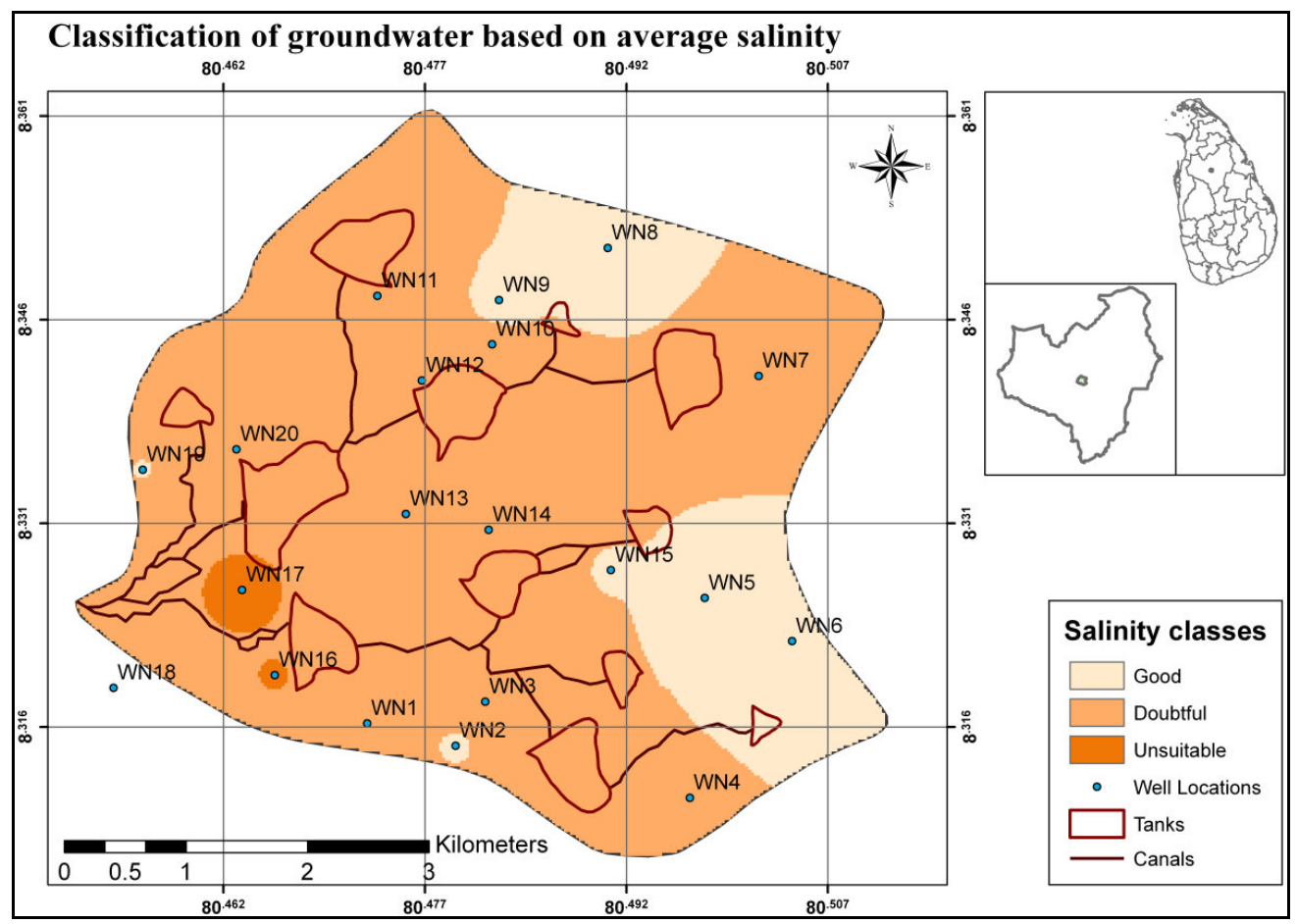

Fig. 4. Spatial variation of average salinity in Malwathu Oya cascade-I.

\section{Sodium hazard}

\section{a) Sodium percentage}

Irrigation water containing large amounts of sodium is of special concern due to effect of sodium on the soil. Excess sodium in water produces undesirable effects of changing soil properties and reducing soil permeability. Hence, the assessment of sodium concentration is necessary while considering the suitability for irrigation (Arshid et al., 2011).

The sodium percentage was calculated using the formula proposed by Wilcox (1955). According to Wilcox (1955), groundwater was grouped based on average percent sodium as excellent $(<20 \%)$, good $(20-40 \%)$, permissible $(40-60 \%)$, doubtful $(60-80 \%)$ and unsuitable 
(>80\%). Out of the selected wells, $10 \%$ had excellent irrigation water quality, $60 \%$ had good irrigation water quality, $25 \%$ had permissible irrigation water quality and $5 \%$ had doubtful irrigation water quality. Similar to salinity, high concentration of sodium was also observed in areas surrounding well no 16 and well no 17. Fig. 5 shows the spatial variation of $\mathrm{Na} \%$ during the study period.

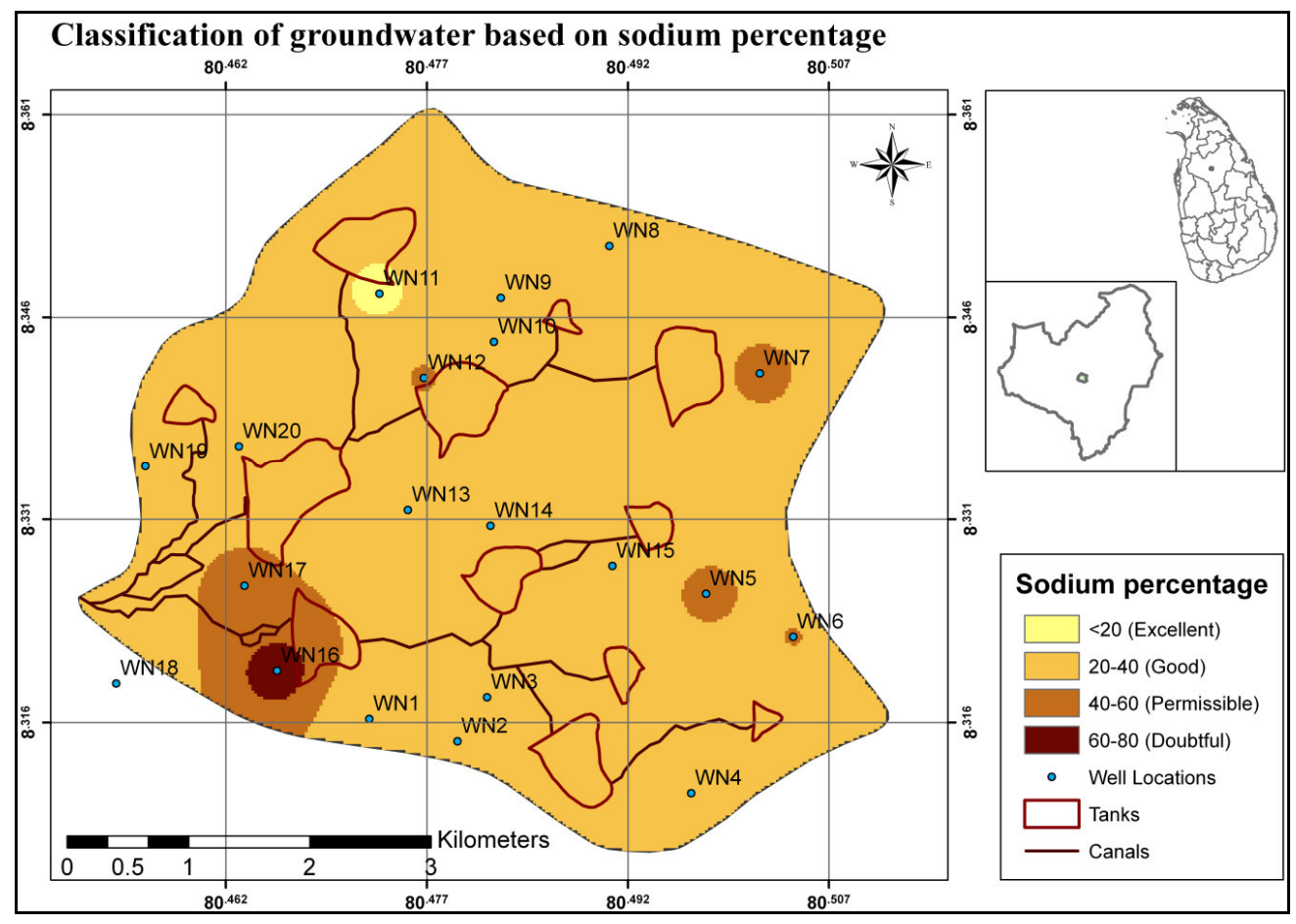

Fig. 5. Spatial distribution of average $\mathrm{Na} \%$ in Malwathu Oya cascade-I.

\section{b) Sodium adsorption ratio (SAR)}

Sodium hazard is also usually expressed in terms of the sodium adsorption ratio (SAR). SAR values of each sample were calculated by the formula proposed by Richards (1954). Groundwater could be classified based on SAR as excellent (0-10), good (10-18), doubtful $(18-26)$ and unsuitable (>26). Classification based on SAR is more realistic than based on $\mathrm{Na} \%$ as SAR indicates the relative magnitude of $\mathrm{Na}$ as compared to $\mathrm{Ca}$ and $\mathrm{Mg}$ in water. $\mathrm{As}$ per the classification based on average SAR values, all the wells fall into excellent category. Accordingly, groundwater in the study area is suitable for irrigation with no danger of exchangeable sodium.

\section{Bicarbonate hazard}

\section{a) Residual sodium carbonate (RSC)}

Bicarbonate hazard is usually expressed in terms of RSC (Residual Sodium Carbonate). In waters having high concentration of bicarbonates, there is a tendency for calcium and magnesium to precipitate as the water in the soil becomes more concentrated. As a result, the 
relative proportion of sodium in the water is increased in the form of sodium bicarbonate. The classification of water quality for irrigation on the basis of RSC was proposed by Eaton (1950). Residual carbonate levels less than $1.25 \mathrm{meq} / \mathrm{L}$ are considered safe. Waters with RSC of 1.25-2.50 meq/L are within the marginal range. It was grouped as good $(<1.25)$, doubtful $(1.25-2.5)$ and unsuitable (>2.5). Based on average RSC, all the samples fall within good category.

\section{Classification of irrigation water}

The US salinity diagram (Richard, 1954) was used to classify the groundwater for irrigation. Combination between EC (salinity hazard) and SAR (sodium hazard) had been used in US salinity diagram. Out of selected wells, $40 \%$ fall under C2-S1, indicating medium salinity and low sodium hazard. These wells can be used for irrigation with most crops on most soils with little danger of exchangeable sodium. Fifty percent (50\%) of the samples fall into C3-S1 category with high salinity and low sodium. These wells cannot be used on soils with restricted drainage. Even with adequate drainage, special management for salinity control may be required and plants with good salt tolerance should be selected. Ten percent (10\%) of the wells fall into C4-S2, indicating very high salinity and medium sodium content in water. It reveals that water is not suitable for irrigation under ordinary conditions. The soil must be permeable, drainage must be adequate and irrigation water must be applied in excess to provide considerable leaching. Therefore, the areas surrounding $60 \%$ of the wells (C3-S1 and C4-S2 classes) can be classified as unsuitable for irrigation under ordinary conditions, which will require improved drainage.

Based on all the measured water quality parameters, $25 \%, 15 \%, 50 \%$ and $10 \%$ of the wells fall into good, permissible, doubtful and unsuitable category for irrigation, respectively (Table 1).

Table 1. Suitability of irrigation water based on all the measured water quality parameters.

\begin{tabular}{lcccccc}
\hline Well no & pH & Salinity & Na\% & SAR & RSC & Suitability \\
\hline 1 & Good & Doubtful & Good & Excellent & Good & Doubtful \\
2 & Good & Good & Good & Excellent & Good & Good \\
3 & Good & Doubtful & Good & Excellent & Good & Doubtful \\
4 & Good & Doubtful & Good & Excellent & Good & Doubtful \\
5 & Good & Good & Permissible & Excellent & Good & Permissible \\
6 & Good & Good & Permissible & Excellent & Good & Permissible \\
7 & Good & Doubtful & Permissible & Excellent & Good & Permissible \\
8 & Good & Good & Good & Excellent & Good & Good \\
9 & Good & Good & Good & Excellent & Good & Good \\
10 & Good & Doubtful & Good & Excellent & Good & Doubtful \\
11 & Good & Doubtful & Excellent & Excellent & Good & Doubtful \\
12 & Good & Doubtful & Permissible & Excellent & Good & Doubtful \\
13 & Good & Doubtful & Good & Excellent & Good & Doubtful \\
14 & Good & Doubtful & Good & Excellent & Good & Doubtful \\
15 & Good & Good & Good & Excellent & Good & Good \\
16 & Good & Unsuitable & Doubtful & Excellent & Good & Unsuitable \\
17 & Good & Unsuitable & Permissible & Excellent & Good & Unsuitable \\
18 & Good & Doubtful & Excellent & Excellent & Good & Doubtful \\
19 & Good & Good & Good & Excellent & Good & Good \\
20 & Good & Doubtful & Good & Excellent & Good & Doubtful \\
\hline
\end{tabular}




\section{CONCLUSIONS}

Based on EC, $35 \%$ of the wells had good quality water, $55 \%$ of the wells had doubtful quality and $10 \%$ of the wells had unsuitable quality. In areas where irrigation quality is doubtful and unsuitable, there is a risk of yield reduction for most commonly cultivated crops like chilli, eggplant, long bean, okra and sesame. Adequate drainage and leaching can be practiced to cultivate sensitive crops. As per the classification based on sodium percentage, $10 \%$ had excellent irrigation water quality, $60 \%$ had good irrigation water quality, and $25 \%$ had permissible irrigation water quality and $5 \%$ had doubtful irrigation water quality. However based on average SAR and RSC values, all the wells fall into excellent and good category, respectively. According to the US salinity hazard diagram, 40\% of the wells had medium salinity and low sodium hazard. These sources can be used for irrigation with most crops on most soils with little danger of exchangeable sodium. Fifty percent of the samples had high salinity and low sodium hazard while $10 \%$ of the samples had very high salinity and medium sodium hazard. This water can be used with adequate drainage and applying special measures for salinity control. Based on all the measured water quality parameters, $25 \%, 15 \%, 50 \%$ and $10 \%$ of the wells fall into good, permissible, doubtful and unsuitable categories for irrigation, respectively. Lower part of the cascade shows high salinity and sodium hazard, which require in-depth study to find out whether it is the case of salt accumulation down the cascade, poor drainage or inherent nature of the soil and the bedrock found in the region.

\section{REFERENCES}

Arshid, J., Aasimah, T., Yousuf, A.R., Akbar, M. and Aabid, H.N. (2011). Geochemistry and irrigation quality of groundwater along river Jhelum in south Kashmir, India. Recent Research in Science and Technology. 3(6), 57-63.

Dharmasena, P.B. (1989). Optimum utilization of the storage in village tanks. Tropical Agriculturist. 145, 01-09.

Dharmasena, P.B. (1991). Present use of land and water resources in village tank farming: A case study in MahaKanumulla cascade. Journal of Soil Sci. Soc. Sri Lanka. 7, 1-17.

Eaton, F.M. (1950). Significance of carbonates in irrigation waters. Soil Sci. 69, 123-133.

Jayakody, A.N. (2006). Large diameter shallow agro-wells - a national asset or a burden for the nation? The Journal of Agricultural Sciences. 2(1), 1-10.

Kendaragama, K.M.A. (2000). Quality of agro-well water in the dry zone- a case study in Anuradhapura district. Journal of Soil Sci. Soc. Sri Lanka. 12, 26-33.

Kumara, K.A.G.M.P., Abeysinghe, N.S. and Kumari, M.K.N. (2011). Groundwater level and quality of Kammalakkulama village in Anuradhapura. Proceedings of the undergraduate research symposium, Faculty of Agriculture, Rajarata University of Sri Lanka, 55.

Perera, A.P.G.R.L., Wijekoon, D.V.K and Senevirathna, A.A.A.K.K. (2002). Water quality of agro-wells in the Anuradhapura district. In: Pathmarajah, S. (Ed.). Proceedings of the symposium on the use of groundwater for agriculture in Sri Lanka, 74-84. 
Perera, K.T., Gunarathna, M.H.J.P. and Ranagalage, M.M. (2011). Evaluation of surface water resources in Malwathu Oya Cascade-I. Proceedings of the undergraduate research symposium, Faculty of Agriculture, Rajarata University of Sri Lanka, 52.

Richard, L.A. (1954). Diagnosis and improvement of saline and alkali soils. Agric. Handbook 60, U.S. Department of Agriculture, Washington.

Tatawat, R.K. and Chandel, C.P.S. (2008). Quality of groundwater of Jaipar city, Rajasthan (India) and its suitability for domestic and irrigation purpose. Appl. Ecol. and Environ. Res. 6(2), 79-88.

Wilcox. L.V. (1955). Classification and use of irrigation waters. U.S. Department of Agriculture Circular 969, Department of Agriculture, Washington. 